\title{
$\bullet$ \\ Diabetes Mellitus with Non-Alcoholic Fatty Liver Disease-Challenges in Nutritional Therapy
}

\section{IJCRR}

Section: Healthcare

ISI Impact Factor

(2019-20): 1.628

IC Value (2019): 90.81 $\operatorname{SJIF}(2020)=7.893$

\section{Suchitra MR ${ }^{1}$, Parthasarathy $S^{2}$}

'Assistant Professor, Department of Chemistry and Biosciences, SASTRA(SRC), Thanjavur -India; 'Professor, Department of Anesthesiology,

Mahatma Gandhi Medical College and Research Institute, Sri Balaji Vidyapeeth, Puducherry -India.

\section{ABSTRACT}

Diabetes mellitus (DM) and non-alcoholic fatty liver disease (NAFLD) are inseparably entwined, each worsening the condition of the other. Different types of drugs are being described to counter the disease. Nutritional challenges are far more in combined illness. We wanted to focus on the intricate difficulties of managing such a comorbid case about diet and nutrition. A detailed search of the articles from Pubmed, Cochrane and Scopus databases were made to consolidate the findings in a concise way to be presentable highlighting the nucleus of the problem. A nominal $10-15 \%$ decrease in the calories will be beneficial in both illnesses. Strict avoidance of excess alcohol and soft drinks is a must. Diet with added fructose should be avoided. Still, garlic with oligofructose is beneficial. Use of vegetable oils rich in polyunsaturated fatty acids will help in decreasing the incidence of fatty liver. The intake of unprocessed food like whole grains, nuts, legumes, fruits and seeds with high fibre content and fewer simple sugars are recommended. Spaced slow intake of restricted calorie diet is ideal. Five planned menus for a 600-calorie diet are given. The diet can be adjusted to $1500-2000$ calories according to the need of the patient. The confounding factors which modify these plans are age, sex, Body mass index and the regular physical activities of each individual. A mildly modified but eatable menu in the diet can be achieved to counter the comorbid conditions of diabetes mellitus and NAFLD. A very low calorie (600 calories/day) diet may be beneficial to NAFLD but needs caution in the incidence of abnormal glycaemic swings. A $10 \%$ reduction in weight is useful in NAFLD.

Key Words: Diabetes, Fatty liver, Nutrition, Diet, Recipes

\section{INTRODUCTION}

Diabetes mellitus is one of the most common non-communicable epidemics ruining the world. India has become the diabetic capital with a maximum number of cases. Nutritional management of diabetes mellitus plays an important role in the control of the disease. There are many complications associated with the disease as it progresses over years. The duration of diabetes increases the incidence of its associated complications. ${ }^{1}$ Non-alcoholic fatty liver disease (NAFLD) is emerging as a new entity with changing lifestyles. The combination of NAFLD with pre-existing dietary modifications for diabetes mellitus (DM) pushes the attending dietician in a fix regarding the modification of diet to arrest the progress of the liver disease. ${ }^{2}$ In this narrative review, we have tried to address the dietary factors which may influence a combined illness.

\section{The genesis of NAFLD in DM}

NAFLD is hepatic steatosis: There should be macrovesicular steatosis in $>5 \%$ of hepatocytes: There should not be any secondary cause of steatosis. The prevalence of NAFLD is around $60 \%$. The most important health problem associated with it is the progression of NAFLD to non-alcoholic steatohepatitis and further to cirrhosis and hepatic cellular carcinoma. The presence of DM worsens the progress of NAFLD and the vice versa is also true and both being proved on a scientific basis beyond doubt. The unexplained interactions between NAFLD, visceral adiposity and insulin resistance thereby its close association with DM is still being explored by scientists. NAFLD disease per se depends on so many factors like genetic predisposition, ethnicity, age, gender, and metabolic status. ${ }^{3}$ Recently a few gene variants have been described where the prevalence of the disease is found to be significantly higher than those who don't possess that

\section{Corresponding Author:}

Dr. S. Parthasarathy, Professor, Department of Anesthesiology, Mahatma Gandhi Medical College and Research Institute, Sri Balaji Vidyapeeth, Puducherry -India; Email: painfreepartha@gmail.com

ISSN: $2231-2196$ (Print)

Received: 30.08 .2020
ISSN: 0975-5241 (Online)

Revised: 23.10 .2020
Accepted: 26.11 .2020

Published: 03.03 .2021 
variant. ${ }^{4}$ In patients with T2D, liver lipogenesis is increased: fatty acid oxidation and triglyceride secretion decreased: the insulin resistance increased: making the liver transform to a fatty liver. Hence, we can decipher that in a genetically susceptible individual, increased insulin resistance and abnormal lipid metabolism in the liver makes patients vulnerable to develop NAFLD than in non-diabetic individuals. We also know that the NAFLD progresses faster to worsen to cirrhosis in diabetics. Hence avoiding the development and the progress of NAFLD in diabetic patients form an essential part of the management of diabetes mellitus. ${ }^{5}$ Still, renal cardiac and neurological complications of DM are well studied, but NAFLD as a dangerous predecessor to hepatocellular carcinoma in uncontrolled patients is not recognized. The presence of NAFLD also increases the cardiovascular complications of DM.

\section{Management of NAFLD in diabetics}

Metformin, glitazones, Gliflozins, gliptins have been prescribed with varying results as targets to NAFLD among the other many drugs used for control of hyperglycaemia. Recent studies have shown more negative results with the use of metformin and NAFLD. Pioglitazone and lobeglitazone are described as insulin sensitizers with peroxisome proliferator-activated receptor (PPAR)- $\gamma$ agonist effects. Both these drugs have been proved to decrease the fat content of the liver over six months. Among the gliptins which are DPP 4 inhibitors, significant decreases in liver enzymes were reported after 16 weeks of treatment of combined NAFLD and T2DM with sitagliptin. Sodium-glucose co-transporter 2 (SGLT2) inhibitors like gliflozins also play a significant role in the arrest of the progress of the disease other than significant $\mathrm{HbAlC}$ reductions. ${ }^{3}$ This part may be due to their weight-reducing potential. Even though many pharmacological interventions are described, weight reduction, dietary changes and lifestyle modifications are essential and form the key management strategy in such patients.

\section{Dietary changes}

Commonly patients who take high carbohydrate diet with an increased portion of soft drinks and meat are more prone to develop NAFLD. Soft drinks are the most common source of simple sugar and its responsible for worsening Intake of polyunsaturated fatty acids is favourable which is not likely to increase the progress of the disease. Intake of simple carbohydrates especially fructose has been incriminated. Foods which are high in added fructose include sauces, salads, sugary drinks, yoghurt, baked and fast foods. Foods which are naturally rich in fructose include honey, dried fruits and fruit juices. ${ }^{6}$ There are some studies which state that artificially added fructose is more dangerous in causing NAFLD than natural resources. ${ }^{7}$ Oligofructose supplementation decreases blood glucose and optimises the lipid profile so that its beneficial to both DM and NAFLD. Garlic and chicory are rich sources of oligofructose. Fruits like apple, guava and Jamun have benefits for both (DM and NAFLD) diseases. ${ }^{8}$ Sitaphal has antidiabetic properties but the calorific content should be kept in mind (100 cal/100 grams). ${ }^{9}$ Certain types of leaves like asparagus which are also rich in oligofructose are not easily available for routine use. In a study, the effectiveness of one-year continuous consumption of an n-3 PUFA rich olive oil resulted in decreased liver enzymes in patients with NAFLD. Hence a fat restriction is also being proved to arrest the progress of the disease. Foods which are rich in PUFA (vegetable oils) like corn oil, flaxseed oil, mustard oil, sunflower oil rice bran oil can be consumed to tackle NAFLD. Regarding the protein part of the diet, the ingestion of red meat is associated with worse prognosis in patients with NAFLD. ${ }^{10}$ Egg white, pulses are a few protein options. The intake of unprocessed food like whole grains, nuts, legumes, fruits and seeds have high fibre content and less simple sugars and they are recommended for NAFLD. Hence a plant-based unrefined high fibre diet is having a definite negative correlation with the progress of the disease to Non-alcoholic steatohepatitis (NASH) and hepatocellular carcinoma (HCC).$^{11}$ Regular coffee consumption is being studied to have an inhibitive effect on the progression of fibrosis in patients with NAFLD when tested using the FibroTest. ${ }^{12}$ To be clear and concise, the carbohydrates should be around $40 \%-50 \%$ of the total calorie intake with a predominant complex carbohydrate-rich in fibre. A maximum of 10 $\%$ is only allowed for simple sugars without fructose. A fatty intake of $30 \%$ with a PUFA or MUFA is preferred than saturated fatty acid intake. A 10-15\% of energy can be gained from protein which is needed to decrease the associated insulin resistance in such patients. ${ }^{13}$ All diabetic patients should have their calories spread over the day and with intermittent healthy snacks and this idea should synchronize with the dietary prescription of NAFLD. A lot of vitamin supplementation like vitamin $\mathrm{E}, \mathrm{C}$ have been studied with varied results. Alpha-tocopherol and ascorbic acid supplements are being tried. ${ }^{14}$ Citrus fruits, green leafy rich foods and nuts can be recommended with caution and a note on their calorie output. Guava, apple and avocados have less calorific value and can be added to the diet. ${ }^{15}$ On a miscellaneous note, bitter gourd, fenugreek with rich fibre content and tofu with soy protein can lessen the damage to liver associated with DM. ${ }^{16}$

\section{Weight reduction}

Weight reduction has been the numero uno factor in managing NAFLD. A $10 \%$ decrease in the calorie need for any patient is essential in the management of NAFLD with DM. this usually causes a weight loss of around $0.5 \mathrm{~kg} /$ week. Any additional calorie restriction may trigger a ketogenic milieu which is detrimental to DM. the very low caloric diet (VLCD) VLCD-450 Kcal/day and 800kcal/d can effectively and safely reduce body weight and improve NAFLD in 12 
weeks in obese 132 Taiwanese participants. ${ }^{17}$ The weight reduction was more than $10 \%$ and the enzyme improvement showed $41 \%$ and $50 \%$ in 450 and 800 calorie groups. Exactly how far this VLCD is clinically practical in patients with normal lifestyle is to be explored. Hence a low-calorie diet of
$1400 \mathrm{kcal} /$ day is easily feasible and achieves the needed in a sufficient period. There should be complete abstinence from alcoholic beverages. The dietary pattern should be spread over a five to six meal times and each meal should be taken slowly over some time but not in haste. ${ }^{18}$

Table 1: Menu with alternate recipes for VLCD in a case of DM with NAFLD

\begin{tabular}{|c|c|c|c|c|c|}
\hline & Morning & Breakfast & Lunch & Evening & Dinner \\
\hline Plan menu 1 & $\begin{array}{l}\text { Green tea without } \\
\text { sugar, walnuts } 2\end{array}$ & $\begin{array}{l}2 \text { idlis with onion } \\
\text { chutney }\end{array}$ & $\begin{array}{l}\text { Half katorie rice with } \\
\text { dhal, Green leafy Veg- } \\
\text { etables, tomato raita }\end{array}$ & $\begin{array}{l}\text { Apple + } \\
\text { Green tea }\end{array}$ & $\begin{array}{l}2 \text { chappathi in olive oil } \\
\text { Garlic chutney }\end{array}$ \\
\hline $500-600 \mathrm{Kcal}$ & 80 & 160 & 180 & 80 & 110 \\
\hline Plan menu 2 & $\begin{array}{l}\text { Black coffee with } \\
\text { chicory with mini- } \\
\text { mal milk without } \\
\text { sugar }\end{array}$ & $\begin{array}{l}\text { Ragi adai or } \\
\text { Ragi dosa } \\
2 \text { in number } \\
\text { With tomato } \\
\text { chutney }\end{array}$ & $\begin{array}{l}\text { Varagu rice pulav } 3 / 4^{\text {th }} \\
\text { katorie } \\
\text { Beans, }\end{array}$ & Avocado & $\begin{array}{l}\text { Rice-flake uppuma } \\
1 / 2 \text { katorie } \\
+ \text { buttermilk 10oml }\end{array}$ \\
\hline $500-600$ Kcal & 30 & 160 & 160 & 80 & 110 \\
\hline Plan menu 3 & Carrot juice & $\begin{array}{l}\text { Fenugreek dosa } 2 \\
\text { - medium size } \\
\text { Garlic chutney }\end{array}$ & $\begin{array}{l}\text { Kuthirai vali } \\
\text { pulav } 3 / 4 \text { th katorie. } \\
\text { Pulses / cooked ground } \\
\text { nuts - 1oo grams } \\
\text {-unfried }\end{array}$ & $\begin{array}{l}\text { vegetable salad } \\
+ \\
\text { coconut water }\end{array}$ & $\begin{array}{l}\text { Dhoklas pieces } 4 \text { with } \\
\text { curd }\end{array}$ \\
\hline 600 - 70oKcal. & 40 & 120 & 250 & 100 & 190 \\
\hline Plan menu - 4 & $\begin{array}{l}\text { Mushroom soup } \\
\text { Or Bermuda grass } \\
\text { juice }\end{array}$ & $\begin{array}{l}\text { Baked fish (2 } \\
\text { pieces) with to- } \\
\text { mato or } \\
\text { Salmon with } \\
\text { spinach }\end{array}$ & $\begin{array}{l}2 \text { hard-boiled eggs, veg- } \\
\text { etable salad }\end{array}$ & Barley soup & $\begin{array}{l}\text { Vegetable oil khichdi } \\
\text { Onion raita }\end{array}$ \\
\hline $500-600 K c a l$ & 40 & 150 & 200 & 50 & 150 \\
\hline Plan menu 5 & $\begin{array}{l}\text { Dilute milk with } \\
\text { chicory coffee } \\
\text { Or watermelon } \\
\text { juice }\end{array}$ & $\begin{array}{l}\text { Sesame baked tofu } \\
\text { (soy)with } \\
\text { Brocolli salad }\end{array}$ & $\begin{array}{l}\text { Cucumber pepper rice } \\
-3 / 4 \text { katorie } \\
\text { Cabbage steamed } 100 \\
\text { grams }\end{array}$ & $\begin{array}{l}\text { Guava fruit } 2 \\
\text { in number or } \\
\text { Jamun fruit } \\
8-10\end{array}$ & $\begin{array}{l}\text { Two roti/ Phulka/ } \\
\text { wheat paratha } \\
\text { Sprouted green gram } \\
\text { dhal gravy }\end{array}$ \\
\hline $600-700$ Kcal & 40 & 120 & 140 & 80 & 250 \\
\hline
\end{tabular}

The menu described is for complete restriction to VLCD so that the calorie intake is around 600 calories. Addition of intake in the number of dosa, idlis or chapathi can be done to increase the calorific value to 1500 calories. The valueadded nutrition in the form of ragi biscuits, bitter gourd pakodas can be added to facilitate control of DM along with regression of NAFLD. The total calorie intake can be easily adjusted from the above described according to the needs of the patient. The diet will vary with patients' age, sex, weight and physical activity.

\section{CONCLUSION}

In patients with combined DM and NAFLD, a strict but cautious calorie restriction with a $10 \%$ weight reduction is more beneficial for the latter. Intake of whole grains, nuts and fibre rich food is good for both. Garlic with oligofructose, chicory, avocados and tofu are liver-friendly dishes. A well-planned dietary pattern with adequate nutritious energy-producing foods but with fewer calories are advised to contain the dreaded combination of two diseases.

\section{ACKNOWLEDGEMENT}

We acknowledge the help of Dr.S.Balachandar, JIPMER, Karaikkal for the critical help in the preparation of the manuscript

Funding: NIL

Conflict of interest: NIL for both authors 
MRS: Generation of the concept and collection of material

SPS: Write-up and overall supervision

\section{REFERENCES}

1. Kaveeshwar SA, Cornwall J. The current state of diabetes mellitus in India. Aus Med J 2014;7(1):45-48.

2. Loomba R, Abraham M, Unalp A, Wilson L, Lavine J, Doo E, et al. Nonalcoholic Steatohepatitis Clinical Research Network. Association between diabetes, family history of diabetes, and risk of nonalcoholic steatohepatitis and fibrosis. Hepatology 2012;56:943-951.

3. Kim KS, Lee BW, Kim YJ, Lee DH, Cha BS, Park CY. Nonalcoholic Fatty Liver Disease and Diabetes: Part II: Treatment. Diabetes Metab J 2019;43(2):127-143.

4. Xia MF, Bian H, Gao X. NAFLD and Diabetes: Two Sides of the Same Coin? The rationale for Gene-Based Personalized NAFLD Treatment. Front Pharmacol 2019;10:877.

5. Arrese M. Nonalcoholic fatty liver disease: liver disease: an overlooked complication of diabetes mellitus. Nat Rev Endocrinol 2010;6(12):660-661.

6. Kargulewicz A, Stankowiak-Kulpa H, Grzymisławski M. Dietary recommendations for patients with nonalcoholic fatty liver disease. Prz Gastroenterol 2014;9(1):18-23.

7. Chiu S, Sievenpiper JL, de Souza RJ, Cozma AI, Mirrahimi A, Carleton AJ, et al. Effect of fructose on markers of non-alcoholic fatty liver disease (NAFLD): a systematic review and meta-analysis of controlled feeding trials. Eur J Clin Nutr 2014; 8(4):416-423.

8. Nseir W, Hellou E, Assy N. Role of diet and lifestyle changes in nonalcoholic fatty liver disease. World J Gastroenterol 2014;20(28):9338-9344.
9. Suchitra MR, Parthasarathy S. Sitaphal: Reemergence. Res J Pharm Biol Chem Sci 2015; 6(3):1560-1565.

10. George ES, Forsyth A, Itsiopoulos C, Nicoll AJ, Ryan M, Sood $\mathrm{S}$, et al. Practical Dietary Recommendations for the Prevention and Management of Nonalcoholic Fatty Liver Disease in Adults. Adv Nutr 2018;9(1):30-40.

11. Romero-Gómez M, Zelber-Sagi S, Trenell M. Treatment of NAFLD with diet, physical activity and exercise. J Hepatol 2017;67(4):829-846.

12. Yamauchi R, Kobayashi M, Matsuda Y, Ojika M, Shigeoka YY, Tou Y, et al. Coffee and caffeine ameliorate hyperglycemia, fatty liver, and inflammatory adipocytokine expression in spontaneously diabetic KK-Ay mice. J Agric Food Chem 2010;58:55975603.

13. Tendler D, Lin S, Yancy WS, Mavropoulos J, Sylvestre P, Rockey DC, et al. The effect of a low-carbohydrate, ketogenic diet on nonalcoholic fatty liver disease: a pilot study. Dig Dis Sci 2007; 52: 589-593.

14. El Hadi H, Vettor R, Rossato M. Vitamin E as a Treatment for Nonalcoholic Fatty Liver Disease: Reality or Myth? Antioxidants (Basel). 2018;7(1):12.

15. Mirmiran P, Amirhamidi Z, Ejtahed HS, Bahadoran Z, Azizi F. Relationship between Diet and Non-alcoholic Fatty Liver Disease: A Review Article. Iran J Public Health 2017;46(8):10071017.

16. Suchitra MR, Parthasarathy S. Effect of administration of fenugreek seeds on HbA1C levels in uncontrolled diabetes mellitus - a randomized controlled trial. Int $\mathrm{J}$ Pharm Tech Res 2015,8(2):180-182.

17. Lin WY, Wu CH, Chu NF, Chang CJ. Efficacy and safety of very-low-calorie diet in Taiwanese: a multicenter randomized, controlled trial. Nutrition 2009;25(11-12):1129-1136.

18. Perdomo CM, Frühbeck G, Escalada J. Impact of Nutritional Changes on Nonalcoholic Fatty Liver Disease. Nutrients 2019;11(3):677. 